\title{
DEVELOPMENT OF A VALID AND RELIABLE INSTRUMENT FOR THE ASSESSMENT OF QUALITY OF LIFE IN ADOLESCENTS WITH CLEFTS - DETECTION OF POTENTIAL MENTAL HEALTH ISSUES
}

\author{
Marko Vuletić ${ }^{1}$, Darko Marčinko², Domagoj Vražić ${ }^{3}$, Milan Miloševićc \\ Emil Dediol $^{5}$ \& Predrag Knežević ${ }^{5}$ \\ ${ }^{I}$ Private practice, Sisak, Croatia \\ ${ }^{2}$ School of Medicine, University of Zagreb, Department of Psychiatry, University Hospital Center Zagreb, Zagreb, Croatia \\ ${ }^{3}$ School of Dental Medicine, University of Zagreb, Department of Periodontology, Zagreb, Croatia \\ ${ }^{4}$ School of Medicine, University of Zagreb , "Andrija Štampar" School of Public Health, Zagreb, Croatia \\ ${ }^{5}$ School of Medicine, University of Zagreb, Department of Oral and Maxillofacial Surgery, \\ University Hospital Dubrava, Zagreb, Croatia
}

received: 23.5.2017;

revised: 5.6.2017;

accepted: 17.8 .2017

\section{SUMMARY}

Background: The rehabilitation of patients with cleft deformities is very complex and unique, and managed by a team of professionals. Quality of life depends on the health, and represents an instrument that examines the disease impact and treatment modalities on the health, integrating an objective assessment of the health status and its subjective experience. Children with clefts are often teased by their peers, and that is the reason why they experience different kinds of psychological distress. Patients with non-syndromic clefts may develop depression and anxiety, hyperactivity, elevated risk of suicide and increased drug abuse in adolescence.

Subjects and methods: Experienced members of a cleft palate team developed a specific questionnaire divided into 2 parts: the first contains the clinical profile of adolescents, and the second part contains questions regarding quality of life. This questionnaire was administered to 73 patients between June 2015 and June 2016, who matched these criteria during their control examinations at the University Hospital Dubrava.

Results: In general, the patient group showed significantly worse scores on majority of answers, specifying that their quality of life is worse compared to the control group. The principal component analysis revealed the presence of three components (factors). The interpretation of the three components was consistent with loadings indicating the component names: Component 1: The relationship with parents, success, society; Component 2: Appearance, and Component 3: Function.

Conclusion: According to our results, we created a specific instrument - The Quality of Life in Adolescents with Cleft Assessment to assess aesthetic and functional results of treatment and quality of life of the operated adolescents with clefts. The adolescents in this study have no psychiatric disorders diagnosed in their medical charts, but results indicate that some of them need help in dealing with future life. Regarding these findings, it will be possible to intervene in the process of treatment and improve the overall outcome of therapy.

Key words: cleft lip/palate - quality of life - surgical treatment-questionnaire - psychiatric disorders

$$
* * * * *
$$

\section{INTRODUCTION}

A cleft is an abnormal gap or space in the upper lip, alveolous or palate which is the most common congenital malformation that affects the orofacial region. This type of deformity can be felt, seen and heard, as it creates a serious affliction to those who have them. According to the research (Magdalenić-Mestrovic \& Bagatin 2005), the incidence of orofacial clefts in Croatia is 1.71 per 1,000 live births, or one child with a cleft in 581 births. It is very similar to the occurence of oral clefts at the global level in white population, occurring in approximately 1:1000 live births (Dixon et al. 2011). Clefts exhibit interesting racial predilections and gender differences, occuring more frequently in Asians than blacks, and boys are more often affected than girls. The exception is an isolated cleft of the palate which more often occurs in girls (Shapira et al. 1999).
The main reason for the split is incomplete connection of facial extensions between the fourth and tenthof pregnancy (Sinko et al. 2005). The etiology of malformationsis multifactorial and associated with environmental andgenetic factors (Wójcicka \& Kobus 2008). Orofacial clefts have a major impact on quality of life including aesthetics, function, psychological factor, growth of the face and dental development.

The rehabilitation of patients with cleft deformities is very complex and unique, and managed by a team of professionals. Specialists in maxillofacial surgery, oral surgery, primary care, otolaryngology, general dentistry, orthodontics, psychiatry, audiology, speech pathology, genetic counseling, psychology and social work often act as members of a cleft palate team to carry out this comprehensive treatment (Kasten et al. 2008). The number of specialists is in correlation with the number and complexity of the problems faced by individuals 
with orofacial clefts. The main aim of this approach is the best possible outcome for the patient and for the family (Millard \& Richman 2001).

The World Health Organization defined health as a state of complete physical, mental and social wellbeing, and not merely the absence of disease and exhaustion. American psychologist Flanagan (1978) is considered the founder of the concept of quality of life in health care. He used the interview as a research method, and so questioned 3,000 adults about aspects of life whose impairment or enhancement effects on their personal satisfaction. Quality of life depends on the health (HRQOL-health related quality of life), and represents an instrument that examines the disease impact and treatment modalities on the health, integrating an objective assessment of the health status and its subjective experience (Testa \& Simonson 1996). In accordance with this definition is the fact that quality of life is influenced by individual personality, and not excluseively by objective external factors (Glavić et al. 2014).

Klassen et al. (2012) in his review mentioned that only generic questionnaires with control groups were used in studies, so it indicates an obvious lack of specific questionnaires that are prepared for patients with clefts in the literature.

The change of appearance of the orofacial region due to craniofacial diseases and conditions as well as their treatment can have significant consequences in the lives of patients, and can result in loss of self-confidence, self-esteem and social stigma (Hunt et al. 2005). Jakovljević et al. (2010.) reported that higher quality of life can improve mental functioning.

Children with clefts are often teased by their peers, and that is the reason why they experience different kinds of psychological distress. Thompson and Kent (2001) reported that facial disfigurment increased levels of depression and anxiety, while Endriga and KappSimon (1999) pointed out that adolescents were affected by cognitive, behavioural and emotional difficulties of clinical concern. The risk of mental health problems in this kind of patients is influenced by different genetic syndromic forms of orofacial clefts causing schizophrenia-like psychotic disorders, mild retardation, autism and ADHD (Schneider et al. 2014). According to the literature, patients with non-syndromic clefts may develop depression and anxiety, hyperactivity, elevated risk of suicide and increased drug abuse in adolescence (Demir et al. 2011, Wehby et al. 2012, Tyler \& Wehby 2013).

In Croatia, there have so far been no studies that process this problem. A questionnaire that examines the quality of life, and that is translated into Croatian and validated is not suited for the age group under 18 years (Petričević et al. 2009). These facts indicate that there is a need for research to examine the quality of life in children with clefts and to also see the results of treatment and health care quality of the team involved in this process.

\section{SUBJECTS AND METHODS}

Experienced members of the cleft palate team including maxillofacial surgeon, oral surgeon, orthodontist, speech therapist and psychiatrist from University Hospital Dubrava, Zagreb, Croatia studied many generic questionnaires that examine the quality of life such as: Child Perceptions Questionnaire for 11- to 14-year-old children (CPQ11-14) (Locker et al. 2005), Michigan Oral Health-Related Quality of Life (MOHRQoL) (Munz et al. 2011), Youth Quality of Life Instrument-Facial Differences module (Edwards et al. 2005) etc. First, a literature review was made through PubMed and MEDLINE for the keywords: „quality of life and clefts“,"quality of life adolescents“, „quality of life questionnaires cleft" etc. The next step was creating questions concerning quality of life assessment in adolescents with clefts. At the beginning, they made about 90 questions that were gradually reduced by all members of the cleft team to the final number of 46 questions that are used in present study.

The Quality of Life in Adolescents with Cleft Assessment (QLACA) questionnaire is divided into 2 parts: the first contains the clinical profile of adolescents (age, gender, cleft type, number of surgical treatments, presence of cleft in family), and the second part contains questions regarding quality of life. Klassen et al. (2012) emphasizes that quality of life is sectioned to physical, psychological and social health, and each part has its subset. All answers in our study were evaluated using the Likert Scale (values from 1 to 5, with 1 representing the best and 5 representing the worst possible attitude).

Patients with clinical diagnosis of different cleft types, which belong to adolescent population of both genders, aged 11-18 years, who were treated by the University Hospital Dubrava cleft team and those with continuity of orthodontic treatment from early age were included in our study. We excluded all patients younger than 11 because this age is used as the limit for puberty, or older than 18 years, who have a non-operated cleft, as well as those with any type of syndrome, learning disorders or other medical problems.

QLACA questionnaire was administered to 80 patients between June 2015 and June 2016, who matched these criteria during their control examinations at the University Hospital Dubrava. Three patients or their parents refused to be part of this study, and 4 patients did not answer to all questions.

Our study in the end included 73 patients with different cleft types (32 males, 41 female). They were divided into 2 age groups: 11-14 years (31 patient) and 15-18 years (42 patients). Most of them had a unilateral cleft lip and palate $(46.6 \%)$, bilateral cleft lip/palate $(27.4 \%)$, isolated cleft palate $(15.1 \%)$ and the rarest was a unilateral cleft lip with $11 \%$.

In the control group, there were 70 participants $(30$ males, 40 females), and they were also adolescents divided in to the same age groups from 11-18 years. 
They were under orthodontic treatment at the University Hospital Dubrava because of different dental malocclusion, without any facial abnormality.

The ethical approval for this study was obtained from the Ethical Committee of the University Hospital Dubrava, Zagreb, Croatia. A written informed consent was signed by each parent/legal guardian for each participant because they were all under the age of 18 .

\section{Statistical methods}

Data is presented in the tables. Kolmogorov-Smirnov test was used to assess data normality. Sociodemographic and clinical characteristics were shown as frequencies with corresponding percentages (categorical variables) or means and standard deviations (quantitative variables). Chi square test was used to assess differences in categorical variables and independent ttest for differences in quantitative variables (answers scores). To investigate the factor structure of the questionnaire used, principal component analysis (PCA) was used. Prior to performing the PCA, the suitability of data for factor analysis was assessed. The inspection of the correlation matrix revealed the presence of many coefficients of 0.3 and above. The Kaiser-Mayer-Oklin value was 0.91 , exceeding the recommended value of 0.6. Bartlett's test of sphericity reached statistical significance, supporting the factorability of the correlation matrix. An inspection of the screeplot, Cattel's scree test and Parallel Analysis were used to additionally confirm the principal component analysis model. Cronbach $\alpha$ coefficient of internal consistency was calculated for each component derived from the PCA. Pearson's and Kendal'stau b (for ordinal and nominal variables) correlation coefficients were calculated to additionally validate the association between component scores and selected clinical variables. All $\mathrm{P}$ values below 0.05 were considered significant. Statistical software IBM SPSS Statistics, version 23, was used in all statistical procedures.

\section{RESULTS}

Socio-demographic and clinical characteristics of the investigated and control group are shown in Table 1. There were no significant differences in age and gender distribution, indicating that other findings are not influenced by these parameters.

Differences in average questions scoring between the patients and control group are shown in Table 2. Some questions regarding cleft problems were not available for the control group and were only administered to the patients group. In general, the patients group showed significantly worse scores on majority of answers, specifying that their quality of life is worse compared to the control group.

Table 1. Socio-demographic and clinical characteristics of investigated and control group

\begin{tabular}{|c|c|c|c|c|c|}
\hline & & \multicolumn{4}{|c|}{ Groups } \\
\hline & & \multicolumn{2}{|c|}{ Patients } & \multicolumn{2}{|c|}{ Control } \\
\hline & & $\mathrm{N}$ & $\%$ & $\mathrm{~N}$ & $\%$ \\
\hline \multirow[t]{2}{*}{ Gender* } & Male & 32 & $43.8 \%$ & 30 & $42.9 \%$ \\
\hline & Female & 41 & $56.2 \%$ & 40 & $57.1 \%$ \\
\hline \multirow[t]{2}{*}{ Age (years)** } & $11-14$ yrs. & 31 & $42.5 \%$ & 26 & $37.1 \%$ \\
\hline & $15-18$ yrs. & 42 & $57.5 \%$ & 44 & $62.9 \%$ \\
\hline \multirow[t]{6}{*}{ Type of cleft } & Bilateral cleft lip & 0 & $0.0 \%$ & & \\
\hline & Bilateral cleft lip/palate & 20 & $27.4 \%$ & & \\
\hline & Unilateral cleft lip & 8 & $11.0 \%$ & & \\
\hline & Unilateral cleft lip/palate & 34 & $46.6 \%$ & & \\
\hline & Isolated cleft palate & 11 & $15.1 \%$ & & \\
\hline & Submucosal cleft palate & 0 & $0.0 \%$ & & \\
\hline \multirow{2}{*}{ Presence of cleft in family } & Yes & 5 & $6.8 \%$ & & \\
\hline & No & 68 & $93.2 \%$ & & \\
\hline \multirow[t]{4}{*}{ Appearance of the nose } & Excellent & 21 & $28.8 \%$ & & \\
\hline & Good & 35 & $47.9 \%$ & & \\
\hline & Satisfactory & 15 & $20.5 \%$ & & \\
\hline & $\mathrm{Bad}$ & 2 & $2.7 \%$ & & \\
\hline \multirow[t]{4}{*}{ Appearance of the lip } & Excellent & 14 & $19.2 \%$ & & \\
\hline & Good & 42 & $57.5 \%$ & & \\
\hline & Satisfactory & 15 & $20.5 \%$ & & \\
\hline & $\mathrm{Bad}$ & 2 & $2.7 \%$ & & \\
\hline \multirow[t]{2}{*}{ Oronasal communication } & Yes & 24 & $32.9 \%$ & & \\
\hline & No & 49 & $67.1 \%$ & & \\
\hline \multirow[t]{3}{*}{ Occlusion (Angle class) } & Class 1 & 33 & $45.2 \%$ & & \\
\hline & Class 2 & 7 & $9.6 \%$ & & \\
\hline & Class 3 & 33 & $45.2 \%$ & & \\
\hline
\end{tabular}

$* \chi^{2}$ test $=0.01 ; \mathrm{df}=1 ; \mathrm{P}=0.906 ; \quad * * \chi^{2}$ test $=0.42 ; \mathrm{df}=1 ; \mathrm{P}=0.516$ 
Table 2. Differences in average questions scoring between patients and control group: independent t-test, answers range from $1=$ completely disagree to $5=$ completely agree

\begin{tabular}{|c|c|c|c|c|c|}
\hline & $\begin{array}{l}\text { Patients } \\
\text { Mean }\end{array}$ & $\begin{array}{c}\mathrm{N}=73 \\
\mathrm{SD}\end{array}$ & $\begin{array}{l}\text { Control } \\
\text { Mean }\end{array}$ & $\begin{array}{c}\mathrm{N}=70 \\
\mathrm{SD}\end{array}$ & $\mathrm{P}$ \\
\hline My taste sense is weakened. & 1.84 & 1.15 & 1.27 & 0.45 & $<0.001$ \\
\hline I argue with my peers. & 2.14 & 1.35 & 1.67 & 1.02 & 0.022 \\
\hline I'm not as good student as I could be. & 2.22 & 1.36 & 2.27 & 1.41 & 0.822 \\
\hline I avoid going out because I am afraid of embarrassing myself. & 1.66 & 1.10 & 1.26 & 0.53 & 0.006 \\
\hline I have concentration difficulties in school. & 2.21 & 1.37 & 1.71 & 1.08 & 0.019 \\
\hline I avoid reading aloud in class. & 2.33 & 1.44 & 1.39 & 0.79 & $<0.001$ \\
\hline I avoid socializing with my peers. & 1.53 & 1.00 & 1.21 & 0.45 & 0.016 \\
\hline $\begin{array}{l}\text { When I get up in the morning. I do not look forward to school } \\
\text { and friends. }\end{array}$ & 1.93 & 1.24 & 1.77 & 0.95 & 0.389 \\
\hline My parents took too much care of me. & 3.32 & 1.40 & 2.76 & 1.40 & 0.019 \\
\hline My parents expect too much of me. & 2.07 & 1.28 & 2.24 & 1.20 & 0.403 \\
\hline My parents think I am not good enough. & 1.92 & 1.32 & 1.60 & 0.97 & 0.104 \\
\hline I do not get on well with my parents. & 1.68 & 1.15 & 1.66 & 1.02 & 0.879 \\
\hline $\begin{array}{l}\text { The cleft does not help me to understand better } \\
\text { other people with disadvantages. }\end{array}$ & 2.03 & 1.19 & NA & NA & NA \\
\hline My peers do not respect me and do not like me. & 1.68 & 1.12 & 1.21 & 0.41 & 0.001 \\
\hline I'm not proud of my achievements so far (school, sports). & 2.16 & 1.44 & 1.83 & 0.95 & 0.104 \\
\hline I give up easily when I do not succeed at something. & 2.08 & 1.28 & 1.83 & 1.01 & 0.191 \\
\hline I feel uncomfortable because of my appearance. & 2.75 & 1.51 & 1.41 & 0.58 & $<0.001$ \\
\hline I avoid laughing normally. & 2.56 & 1.41 & 1.60 & 0.92 & $<0.001$ \\
\hline I feel depressed and sad. & 1.95 & 1.21 & 1.34 & 0.59 & $<0.001$ \\
\hline Other children mock me. & 2.04 & 1.23 & 1.29 & 0.64 & $<0.001$ \\
\hline I have been asked questions about my appearance. & 3.19 & 1.42 & NA & NA & NA \\
\hline My appearance affects my relationship with girls / boys. & 2.93 & 1.48 & 1.54 & 0.88 & $<0.001$ \\
\hline I'm not satisfied with my nose. & 3.15 & 1.48 & 1.31 & 0.55 & $<0.001$ \\
\hline I'm not satisfied with my lip. & 3.16 & 1.43 & 1.39 & 0.67 & $<0.001$ \\
\hline $\begin{array}{l}\text { I have to work harder than other people because } \\
\text { of my appearance. }\end{array}$ & 2.34 & 1.36 & NA & NA & NA \\
\hline $\begin{array}{l}\text { I think that I have more difficulties finding friends because } \\
\text { of my appearance. }\end{array}$ & 2.00 & 1.34 & 1.24 & 0.49 & $<0.001$ \\
\hline People who meet me do not forget my appearance. & 2.37 & 1.34 & NA & NA & NA \\
\hline $\begin{array}{l}\text { I do not like looking at myself in photographs because } \\
\text { of my appearance. }\end{array}$ & 2.38 & 1.24 & 1.57 & 0.79 & $<0.001$ \\
\hline $\begin{array}{l}\text { I should have further surgery in the future } \\
\text { to improve my appearance. }\end{array}$ & 3.47 & 1.42 & NA & NA & NA \\
\hline I would like to change some things about myself. & 3.62 & 1.15 & 2.04 & 0.86 & $<0.001$ \\
\hline $\begin{array}{l}\text { I think I will have more difficulties finding a girlfriend / } \\
\text { boyfriend than my peers. }\end{array}$ & 3.08 & 1.45 & 1.67 & 0.90 & $<0.001$ \\
\hline I think I'm shy in company. & 2.63 & 1.37 & 1.87 & 1.14 & $<0.001$ \\
\hline I have trouble chewing food. & 1.96 & 1.07 & 1.56 & 0.56 & 0.006 \\
\hline My breath is unpleasant. & 2.15 & 1.04 & 1.77 & 0.80 & 0.016 \\
\hline Food remains between my teeth. & 3.25 & 1.20 & 3.27 & 1.18 & 0.901 \\
\hline My oral cavity is sore. & 1.75 & 1.08 & 1.49 & 0.58 & 0.068 \\
\hline My gums bleed. & 2.05 & 1.12 & 1.81 & 0.98 & 0.174 \\
\hline I am worried because of about the condition of my teeth. & 3.05 & 1.55 & 1.71 & 0.90 & $<0.001$ \\
\hline $\begin{array}{l}\text { People sometimes do not understand me because } \\
\text { I have difficulties pronouncing words. }\end{array}$ & 3.01 & 1.50 & NA & NA & NA \\
\hline I feel uncomfortable talking to others. & 2.12 & 1.31 & 1.40 & 0.55 & $<0.001$ \\
\hline I feel that my cleft looks worse than in other children. & 1.95 & 1.23 & NA & NA & NA \\
\hline My life is much worse in comparison with my peers. & 1.95 & 1.12 & 1.30 & 0.49 & $<0.001$ \\
\hline I'm not satisfied with my speech. & 2.85 & 1.41 & NA & NA & NA \\
\hline I am worried about my future. & 2.71 & 1.38 & 1.83 & 1.14 & $<0.001$ \\
\hline It seems to me that everyone else is better than me. & 2.10 & 1.19 & 1.47 & 0.70 & $<0.001$ \\
\hline
\end{tabular}

NA: not available (for control group) 
Table 3. Principal components analysis with corresponding Cronbach $\alpha$ coefficients for each factor: highest loadings coefficients for each factor were bolded

The relationship

with parents,

Appearance Function

success, society

I'm not proud of my achievements so far (school, sports).
My parents think I am not good enough.

When I get up in the morning, I do not look forward to school and friends.

I do not get on well with my parents.

I'm not as good student as I could be.

My peers do not respect me and do not like me.

I have concentration difficulties in school.

I avoid socializing with my peers.

I avoid going out because I am afraid of embarrassing myself.

I give up easily when I do not succeed at something.

My parents expect too much of me.

I avoid reading aloud in class.

I argue with my peers.

The cleft does not help me to understand better other people

with disadvantages.

My taste sense is weakened.

My parents took too much care of me.

My appearance affects my relationship with girls / boys.

I have been asked questions about my appearance.

I'm not satisfied with my lip.

I would like to change some things about myself.

I'm not satisfied with my nose.

I do not like looking at myself in photographs because of my appearance.

I feel depressed and sad.

I think I will have more difficulties finding a girlfriend / boyfriend than my peers.

I avoid laughing normally.

I should have further surgery in the future to improve my appearance.

People who meet me do not forget my appearance.

I have to work harder than other people because of my appearance.

I think that I have more difficulties finding friends because of my appearance.

I feel uncomfortable because of my appearance.

Other children mock me.

I think I'm shy in company.

I am worried because of about the condition of my teeth

I have trouble chewing food

I'm not satisfied with my speech.

My life is much worse in comparison with my peers.

It seems to me that everyone else is better than me.

I feel uncomfortable talking to others.

My breath is unpleasant.

My gums bleed.

People sometimes do not understand me because

I have difficulties pronouncing words.

I am worried about my future.

My oral cavity is sore.

I feel that my cleft looks worse than in other children.

Food remains between my teeth.

Cronbach $\alpha$ coefficients

\begin{tabular}{|c|c|c|}
\hline 0.842 & 0.099 & 0.092 \\
\hline 0.749 & 0.046 & 0.138 \\
\hline 0.697 & 0.302 & -0.033 \\
\hline 0.684 & -0.011 & 0.151 \\
\hline 0.659 & -0.008 & 0.020 \\
\hline 0.640 & 0.211 & 0.191 \\
\hline 0.629 & 0.065 & -0.050 \\
\hline 0.627 & 0.293 & 0.104 \\
\hline 0.587 & 0.385 & 0.189 \\
\hline 0.561 & 0.043 & 0.158 \\
\hline 0.556 & 0.018 & 0.266 \\
\hline 0.527 & 0.318 & -0.015 \\
\hline 0.482 & -0.077 & 0.349 \\
\hline 0.478 & -0.221 & 0.163 \\
\hline 0.422 & -0.281 & 0.305 \\
\hline 0.357 & -0.001 & 0.107 \\
\hline 0.050 & 0.802 & 0.028 \\
\hline-0.081 & 0.727 & 0.025 \\
\hline 0.105 & 0.718 & 0.035 \\
\hline-0.005 & 0.670 & -0.063 \\
\hline-0.027 & 0.646 & 0.107 \\
\hline 0.196 & 0.631 & 0.406 \\
\hline 0.241 & 0.607 & 0.480 \\
\hline 0.202 & 0.595 & 0.050 \\
\hline-0.002 & 0.583 & 0.400 \\
\hline 0.010 & 0.573 & 0.201 \\
\hline 0.057 & 0.565 & 0.081 \\
\hline 0.054 & 0.532 & 0.303 \\
\hline 0.417 & 0.505 & 0.374 \\
\hline-0.073 & 0.496 & 0.440 \\
\hline 0.355 & 0.460 & 0.336 \\
\hline 0.203 & 0.359 & 0.029 \\
\hline-0.218 & 0.086 & 0.691 \\
\hline 0.068 & 0.008 & 0.607 \\
\hline 0.244 & 0.089 & 0.586 \\
\hline 0.352 & 0.367 & 0.550 \\
\hline 0.465 & 0.340 & 0.515 \\
\hline 0.150 & 0.371 & 0.513 \\
\hline 0.271 & -0.022 & 0.501 \\
\hline 0.188 & 0.063 & 0.488 \\
\hline 0.282 & 0.075 & 0.427 \\
\hline 0.293 & 0.238 & 0.423 \\
\hline 0.341 & 0.109 & 0.403 \\
\hline 0.252 & 0.295 & 0.383 \\
\hline-0.103 & 0.221 & 0.367 \\
\hline 0.891 & 0.903 & 0.829 \\
\hline
\end{tabular}

*The relationship with parents, success, society 
The principal component analysis revealed the presence of three components (factors) with eigenvalues exceeding 1. An inspection of the screeplot revealed a clear break after the third component. Based on the Cattel's scree test, it was decided to retain three components for further investigation. This was further supported by the results of Parallel Analysis, which showed only three components exceeding the corresponding criterion values for the randomly generated data matrix of the same size ( 45 variables $x 73$ respondents).

The three component solution explained a total of $41.9 \%$ of the variance, explaining $25.7 \%, 10.6 \%$ and $5.6 \%$ of the variance respectively. The varimax rotation was performed to aid in the interpretation of these three components. The rotated solution discovered the presence of a simple structure, with all components showing a number of strong loadings and all variables loading substantially on only one component (factor) (Table 3). The interpretation of the three components was consistent with loadings indicating the component names: Component 1: The relationship with parents, success, society; Component 2: Appearance, and Component 3: Function. Cronbach $\alpha$ coefficient of internal consistency was calculated for each component: the lowest Cronbach $\alpha$ coefficient (0.829) is for the Function, and it is still highly over 0.7 (lowest acceptable value). The results of this analysis support the use of these three components as separate scales.

Table 4. Descriptive statistics and percentile distribution of total component scores among patients

\begin{tabular}{|c|c|c|c|c|}
\hline & & $\begin{array}{l}\text { The relationship with parents, } \\
\text { success, society }\end{array}$ & Appearance & Function \\
\hline $\mathrm{N}$ & & 73 & 73 & 73 \\
\hline Mean & & 26.24 & 43.17 & 34.43 \\
\hline SD & & 19.53 & 21.82 & 17.99 \\
\hline Minimum & & 0.00 & 6.25 & 7.69 \\
\hline Maximum & & 75.00 & 96.88 & 80.77 \\
\hline Percentiles & $\begin{array}{l}25 \\
50 \\
75\end{array}$ & $\begin{array}{l}10.94 \\
20.31 \\
35.16\end{array}$ & $\begin{array}{l}26.56 \\
40.63 \\
59.38\end{array}$ & $\begin{array}{l}20.19 \\
32.69 \\
47.12\end{array}$ \\
\hline
\end{tabular}

Table 5. Correlation coefficients between component scores and selected clinical variables: Pearson's and Kendal'stau_b coefficients

\begin{tabular}{|c|c|c|c|c|}
\hline & & $\begin{array}{l}\text { The relationship with } \\
\text { parents, success, society }\end{array}$ & Appearance & Function \\
\hline $\begin{array}{l}\text { The relationship with parents, } \\
\text { success, society }\end{array}$ & $\begin{array}{c}\text { Correlation Coefficien } \\
\text { P }\end{array}$ & 1.000 & $\begin{array}{l}0.221 \\
0.007\end{array}$ & $\begin{array}{r}0.392 \\
<0.001\end{array}$ \\
\hline Appearance & $\begin{array}{c}\text { Correlation Coefficient } \\
\text { P }\end{array}$ & $\begin{array}{l}0.221 \\
0.007\end{array}$ & 1.000 & $\begin{array}{r}0.350 \\
<0.001\end{array}$ \\
\hline Function & $\begin{array}{c}\text { Correlation Coefficient } \\
\text { P }\end{array}$ & $\begin{array}{r}0.392 \\
<0.001\end{array}$ & $\begin{array}{r}0.350 \\
<0.001\end{array}$ & 1.000 \\
\hline Type of cleft & $\begin{array}{c}\text { Correlation Coefficient } \\
\text { P }\end{array}$ & $\begin{array}{r}-0.103 \\
0.261\end{array}$ & $\begin{array}{r}-0.177 \\
0.051\end{array}$ & $\begin{array}{l}0.000 \\
1.000\end{array}$ \\
\hline Number of operations & $\begin{array}{c}\text { Correlation Coefficient } \\
\text { P }\end{array}$ & $\begin{array}{l}0.060 \\
0.483\end{array}$ & $\begin{array}{l}0.166 \\
0.052\end{array}$ & $\begin{array}{l}0.165 \\
0.056\end{array}$ \\
\hline Presence of cleftin family* & $\begin{array}{c}\text { Correlation Coefficient } \\
\text { P }\end{array}$ & $\begin{array}{l}0.163 \\
0.097\end{array}$ & $\begin{array}{l}0.059 \\
0.548\end{array}$ & $\begin{array}{l}0.079 \\
0.425\end{array}$ \\
\hline Worse appearance of the nose & $\begin{array}{c}\text { Correlation Coefficient } \\
\text { P }\end{array}$ & $\begin{array}{l}0.042 \\
0.650\end{array}$ & $\begin{array}{r}0.355 \\
<0.001\end{array}$ & $\begin{array}{l}0.177 \\
0.056\end{array}$ \\
\hline Worse appearance of the lip & $\begin{array}{c}\text { Correlation Coefficient } \\
\text { P }\end{array}$ & $\begin{array}{l}0.090 \\
0.334\end{array}$ & $\begin{array}{l}0.249 \\
0.007\end{array}$ & $\begin{array}{l}0.134 \\
0.150\end{array}$ \\
\hline Oronasal communication $*$ & $\begin{array}{c}\text { Correlation Coefficient } \\
\text { P }\end{array}$ & $\begin{array}{l}0.082 \\
0.404\end{array}$ & $\begin{array}{l}0.175 \\
0.072\end{array}$ & $\begin{array}{l}0.017 \\
0.865\end{array}$ \\
\hline Occlusion (Angle class) & $\begin{array}{c}\text { Correlation Coefficient } \\
\text { P }\end{array}$ & $\begin{array}{l}0.115 \\
0.227\end{array}$ & $\begin{array}{l}0.147 \\
0.120\end{array}$ & $\begin{array}{l}0.197 \\
0.039\end{array}$ \\
\hline Gender* & $\begin{array}{c}\text { Correlation Coefficient } \\
\text { P }\end{array}$ & $\begin{array}{r}-0.008 \\
0.938\end{array}$ & $\begin{array}{l}0.114 \\
0.243\end{array}$ & $\begin{array}{r}-0.005 \\
0.960\end{array}$ \\
\hline Age (years) & $\begin{array}{c}\text { Correlation Coefficient } \\
\text { P } \\
\end{array}$ & $\begin{array}{r}-0.157 \\
0.070 \\
\end{array}$ & $\begin{array}{l}0.041 \\
0.631\end{array}$ & $\begin{array}{r}-0.006 \\
0.942 \\
\end{array}$ \\
\hline
\end{tabular}

\footnotetext{
* Kendal's tau_b correlation coefficients
} 
Descriptive statistics and percentile distribution of total component scores among patients are shown in Table 4. Correlation coefficients between component scores and selected clinical variables are shown in Table 5. Indicating significant positive correlation coefficients between appearance assessment of the nose $(\mathrm{r}=0.355$; $\mathrm{P}<0.001)$ and the lip $(\mathrm{r}=0.249 ; \mathrm{P}=0.007)$ with Component 2: Appearance, and Occlusion - Angle class with Component 3: Function $(r=0.197 ; \mathrm{P}=0.039)$. These correlations additionally determine the values of each scale in clinical assessment of patients with cleft palate.

\section{DISCUSSION}

According to our results, the Quality of Life in Adolescents with Cleft Assessment (QLACA) questionnaire is a valid and reliable instrument for the quality of life assessment in adolescents between 11 and 18 years old with clefts. This study emphasizes variables that have a negative effect on quality of life in adolescents with clefts, and has very good psychometric properties.

The QLACA questionnaire showed that there is no significant gender and age difference between the patients and control group and within cleft group, while in the study (Bos \& Prahl 2011), there is only age difference, especially in the group 12-15 years. Majority of studies (Hunt et al. 2006, Damiano et al. 2007, KappSimon et al. 1992) that are researching quality of life in children with clefts showed worse scores of the patient group compared to the control group. Table 2 indicates that almost all answers of the control group had better scores, except those reffering to the cleft that were excluded. Wehby et al. (2006) reports that health professionals who treat children with clefts noticed that these children have a lower health-related quality of life.

Doctors or health professionals that are involed in the process of healing patients with clefts implement the approach of person-centered medicine, which emphasises medical care to the social, psychological and biological aspects of health (Pfeifer \& Cox 2007). Jakovljević (2013) reported that it is very detrimental to treat a disease as only a somatic disorder without treating the whole person. The disease has to be cured, but the patient has to be healed so the focus should be on the disease and the personality of the patient (Jakovljević \& Ostojić 2015).

The factor analysis of our results revealed three components exceeding the corresponding criterion values. The components are: 1- the relationship with parents, success, society; 2- appearance and 3- function. These three components are subsets of conceptual quality of life framework (Klassen et al. 2012) which consists of three domains: physical, psychological and social health. The component function is a subset of physical health, the appearance of psychological health, and the relationship with parents, success and society are subsets of social health.
In the component function, the patient group reported low scores of their satisfaction with speech and oral status, complaining about difficulties while communicating with others or while eating food and keeping their oral hygiene. Clinical manifestations of orofacial clefts are consistent with these findings, especially hypernasality of speech which is a repercussion of oronasal fistulas and/or velopharyngeal incompetence. Millard \& Richman (2001) noted that speech of children with clefts is related to the overall adjustment, low self-esteem, self-perceived depressive symptoms and anxiety.

In our study, adolescents with clefts are very worried about their appearance, especially with their nose. They feel sad and less socially acceptable than their peers. This is in consistence with the findings of Turner et al. (1997) that the physical appearance seems to be a big problem, and that children with clefts have a problem with relating to peers.

By analyzing answers reffering to the appearance of cleft group, and comparing with their control group, from our QLACA questionnaire, it is noticeable that some of them are showing initial signs of psychopathology that can be manifested in adulthood. Hunt et al. (2006) reported that adolescents with cleft have shown more depression symptoms than the control group. These results present an important move in assessing depression. The findings of Reinherz et al. (1989) explained that a cleft is considered to be an illness in the minds of patients, so that may explain an increase in depressions at that age group. Adults with cleft suffer from anxiety and depression twice as often as the control group (Ramstad et al. 1995). The cleft group reported they were mocked by their peers, and according to Storch et al. (2003), the frequency of bullying is in a positive correlation with general anxiety, depression symptoms and loneliness.

Christodoulou et al. (2008) quoted great Greek philosophers and physicians who taught that ,it is impossible for the part to be well if the whole is not well“", as can also be seen from the results of our study. Patients with clefts, much like other patients in medicine, are not only carriers of disease and illness; they are also human beings with their sense of life, values and purpose in addition to disease experience (Jakovljević 2007, Christodoulou et al. 2008).

Our results confirm that adolescents mostly agree with the question whether they need further surgery in the future to improve their appearance. Semb et al. (2005) reported that $65 \%$ of patients wanted more surgical treatment, relating perhaps to higher levels of dissatisfaction with outcomes of the lip and nose. Contrary to this fact, Broder \& Wilson-Genderson (2007) described that satisfaction with appearance often increased with patients' age.

Social health is affected by physical difficulties, so adolescents with orofacial clefts often demonstrate social inhibition (Kapp-Simon \& McGuire 1997). Based on the analysis of the answers from QLACA ques- 
tionnaire, the results were quite encouraging, showing that the relationship between adolescents with clefts and their family is quite positive on average. These findings are similar with the study by Piombino et al. (2014) made in three centers in Italy.

\section{CONCLUSION}

We created a specific instrument - the QLACA questionnaire to assess the aesthetic and functional results of treatment and quality of life of the operated adolescents with clefts.

Although the adolescents in this study have no psychiatric disorders diagnosed in their medical charts, the results indicate that some of them need help in dealing with future life. Previous research has shown that it is important that newly diagnosed psychiatric conditions that appear in childhood or adolescence must be treated to reduce their dissemination in adulthood. The QLACA questionnaire may be useful as a base for detection of potential mental health issuses. Regarding these findings, it will be possible to intervene in the process of treatment and improve the overall outcome of therapy. Since these are the most common malformations of the head and neck, an emphasis should be placed on the need for creation of guidelines for the treatment, including more specialists, as well as further improvement of the entire health system.

\section{Acknowledgements: None.}

\section{Conflict of interest: None to declare.}

\section{Contribution of individual authors:}

Marko Vuletić: Design of the study, subjects recruitment, analysis and interpretation of data, writing the manuscript, literature searches;

Darko Marčinko: Design of the study, analysis and interpretation of data, statistical analyses;

Domagoj Vražić: Writing the manuscript, literature searches;

Milan Milošević: Statistical analyses, writing the manuscript;

Emil Dediol: Subjects recruitment, literature searches;

Predrag Knežević: Design of the study, subjects recruitment, analysis and interpretation of data.

\section{References}

1. Bos A \& Prahl C: Oral health-related quality of life in Dutch children with cleft lip and/or palate. Angle Orthod 2011; 81:865-871.

2. Broder HL \& Wilson-Genderson M: Reliability and convergent and discriminant validity of the child oral health impact profile (cohip child's version). Community Dent Health 2007; 35:20-31.
3. Christodoulou G, Fulford B \& Mezzich JE: Psychiatry for the person and its conceptual bases. International Psychiatry 2008; 5:1-3.

4. Damiano PC, Tyler MC, Romitti PA, Momany ET, Jones $M P$, Canady JW et al.: Health-related quality of life among preadolescent children with oral clefts: the mother's perspective. Pediatrics 2007; 120:283-290.

5. Demir T, Karacetin G, Baghaki S, Aydin Y. Psychiatric assessment of children with nonsyndromic cleftlip and palate. General hospital psychiatry. 2011; 33:594-603.

6. Dixon MJ, Marazita ML, Beaty TH \& Murray JC: Cleft lip and palate: understanding genetic and environmental influences. Nat Rev Genet 2011; 12:167-178.

7. Edwards TC, Patrick DL, Topolski TD, Aspinall CL, Mouradian WE \& Speltz ML: Approaches to craniofacialspecific quality of life assessment in adolescents. Cleft Palate Craniofac J 2005; 42:19-24.

8. Endriga MC, Kapp-Simon KA: Psychological issues in craniofacial care: state of the art. Cleft PalateCraniofacial Journal 1999; 36:3-11.

9. Flanagan $J: A$ research approach to improving our quality of life. Am Psychol 1978; 33:138-147.

10. Glavić Z, Galić $S$ \& Krip M: Quality of life and personality traits in patients with colorectal cancer. Psychiatr Danub 2014; 26:172-180.

11. Hunt $O$, Burden D, Hepper $P$ \& Johnston $C$ : The psychosocial effects of cleft lip and palate: a systematic review. Eur J Orthod 2005; 27:274-285.

12. Hunt $O$, Burden D, Hepper P, Stevenson $M \&$ Johnston C: Self-reports of psychosocial functioning among children and young adults with cleft lip and palate. Cleft Palate Craniofac J 2006; 43:598-605.

13. Jakovljević M, Tomić Z, Maslov B \& Skoko I: New image of psychiatry, mass media impact and public relations. Psychiatr Danub 2010; 22:145-148.

14. Jakovljević M: How to increase treatment effectiveness and efficiency in psychiatry: Creative psychopharmacotherapy - Part 2: Creating favourable treatment context and fostering patients' creativity. Psychiatr Danub 2013; 25:274-279.

15. Jakovljević $M$ \& Ostojić L: Person-centered medicine and good clinical practice: disease has to be cured, but the patient has to be healed. Psychiatr Danub 2015; 27:546-549.

16. Jakovljevic $M$ : The brave new psychiatry: A pluralistic integrating transdisciplinary approach in theory and practice. Psychiatr Danub 2007; 19:262-269.

17. Kapp-Simon KA, Simon DJ \& Kristovich S: Selfperception, social skills, adjustment, and inhibition in young adolescents with craniofacial anomalies. Cleft Palate Craniofac J 1992; 29:352-356.

18. Kapp-Simon KA \& McGuire DE: Observed social interaction patterns in adolescents with and without craniofacial conditions. Cleft Palate Craniofac J 1997; 34:380-384

19. Kasten EF, Schmidt SP, Zickler CF, Berner E, Damian LAK, Christian GM, et al.: Team care of the patient with cleft lip and palate. Curr Probl Pediatr Adolesc Health Care 2008; 38:138-158.

20. Klassen AF, Tsangaris E, Forrest CR, Wong KWY, Pusic $A L$, Cano SJ et al.: Quality of life of children treated for cleft lip and/or palate: A systematic review. J Plast Reconstr Aesthet Surg 2012; 65:547-557. 
21. Locker D, Jokovic A \& Tompson B: Health-related quality of life of children aged 11 to 14 years with orofacial conditions. Cleft Palate Craniofac J 2005; 42:260-266.

22. Magdalenić-Meštrović $M$ \& Bagatin $M:$ An epidemiological study of orofacial clefts in Croatia 1988-1998. J Craniomaxillofac Surg 2005; 33:85-90.

23. Millard $T \&$ \& Richman C: Different cleft conditions, facial appearance, and speech: relationship to psychological variables. Cleft Palate Craniofac J 2001; 38:68-75.

24. Munz SM, Edwards SP \& Inglehart MR: Oral healthrelated quality of life, and satisfaction with treatment and treatment outcomes of adolescents/young adults with cleft lip/palate: an exploration. Int J Oral Maxillofac Surg 2011; 40:790-796.

25. Petričević N, Čelebić A, Papić M \& Rener-Sitar K: The Croatian version of the Oral Health Impact Profile Questionnaire. Coll Antropol 2009; 33:841-847.

26. Pfeifer HR \& Cox J: The man and his message. In Cox J, Campbell $A V$ \& Fulford BKWM (eds): Medicine of the Person - Faith, Science and Values in Health Care Provision, 33-45. Jessica Kingsley Publishers, London \& Philadelphia, 2007.

27. Piombino P, Ruggiero $F$, Dell'Aversana Orabona $G$, Scopelliti D, Bianchi A, De Simone F, et al.: Development and validation of the quality-of-life adolescent cleft questionnaire in patients with cleft lip and palate. $J$ Craniofac Surg 2014; 25:1757-1761.

28. Ramstad T, Otten E, Shaw WC: Psychosocial adjustment in Norwegian adults who had undergone standardised treatment of complete cleft lip and palate. Part II. Selfreported problems and concerns with appearance. Scandinavian Journal of Plastic and Reconstructive Surgery and Hand Surgery 1995; 29:329-336.

29. Reinherz HZ, Stewart-Berghauer G, Pakiz B, Frost AK, Moeykens BA, Holmes WM: The relationship of early risk and current mediators to depressive symptomatology in adolescence. J Am Acad Child Psychiatry 1989; 28:942-947.

30. Schneider M, Debbane M, Bassett AS, Chow EW, Fung $W L$, van den Bree $M$, et al: Psychiatric disorders from childhood to adulthood in 22 11.2 deletion syndrome: results from the International Consortium on Brain and Behavior in 22q11.2 Deletion Syndrome. The American journal of psychiatry 2014; 171:627-39.

31. Semb G, Brattström V, Mølsted K, Prahl-Andersen B, Zuurbier P, Rumsey $N$, et al.: The Eurocleft study: intercenter study of treatment outcome in patients with complete cleft lip and palate. Part 4: relationship among treatment outcome, patient/parent satisfaction, and the burden of care. Cleft Palate Craniofac J 2005; 42:83-92.

32. Shapira Y, Lubit E, Kuftinec MM \& Borell G: The distribution of clefts of the primary and secondary palates by sex, type, and location. Angle Orthod 1999; 69:523528.

33. Sinko K, Jagsch R, Preschtl V, Watzinger F, Hollman K \& Baumann A: Evaluation of esthetic, functional and quality-of life outcome in adult cleft lip and palate patients. Cleft Palate Craniofac J 2005; 42:355-361.

34. Storch EA, Bravata EA, Storch JB, Johnson JH, Roth DA, Roberti JW: Psychosocial adjustment in early adulthood: the role of teasing and father support. Child Study J 2003; 33:153-163.

35. Testa MA \& Simonson DC: Assesment of quality-of-life outcomes. N Engl J Med 1996; 334:835-840.

36. Thompson A, Kent G: Adjusting to disfi gurement: processes involved in dealing with being visibly different. Clinical Psychology Review 2001; 21:663-682.

37. Turner SR, Thomas $P W$, Dowell T, Rumsey $N$ \& Sandy JR: Psychological outcomes amongst cleft patients and their families. Br J Plast Surg 1997; 50:1-9.

38. Tyler MC, Wehby GL, Robbins JM, Damiano PC: Separation Anxiety in Children Ages 4 Through 9 with Oral Clefts. Cleft Palate Craniofac J 2013; 50:520-7.

39. Wehby GL, Tyler MC, Lindgren S, Romitti P, Robbins J, Damiano P: Oral clefts and behavioral health of young children. Oral Dis 2012; 18:74-84.

40. Wehby GL, Ohsfeldt RL \& Murray JC: Health professionals' assessment of health-related quality of life values for oral clefting by age using a visual analogue scale method. Cleft Palate Craniofac J 2006; 43:383-391.

41. Wójcicka $K$ \& Kobus K. Etiopathogenesis of Lip, Alveolar Process and Palate Clefts. Pol J Surg 2008; 80:546-552.

Correspondence:

Marko Vuletić DMD

Private practice

Žitna 8, 44000 Sisak, Croatia

E-mail:vulesk@gmail.com 